\title{
Extreme androgen resistance in a kindred with a novel insertion/deletion mutation in exon 5 of the androgen receptor gene
}

Received: 18 December 2002/ Accepted: 12 April 2003/Published online: 6 June 2003

(C) The Japan Society of Human Genetics and Springer-Verlag 2003

\begin{abstract}
Androgen insensitivy syndrome (AIS) is the most frequent cause of male pseudohermaphroditism resulting from target-organ resistance to androgen action. Individuals bearing the complete form of the disease (CAIS) present a female phenotype and a lack of pubic and axillary hair. In the present study, four 46, XY patients born in two generations from a kindred with a history of AIS were examined for genetic abnormalities in the androgen receptor gene $(A R)$. All eight exons encoding the AR protein were individually amplified from genomic DNA followed by a mutation screening with single-strand conformation polymorphism analysis. Sequencing of the mutant $A R$ revealed a novel insertion/deletion mutation in exon 5. A deletion of $7 \mathrm{bp}$ is replaced by an insertion of 11 nucleotides, which represents a duplication of the adjacent downstream sequence. The mutation g.2640_2646delAGGATGC/2652_2662insTTCGCCCCTGA, results in a frameshift that introduces a premature termination signal TGA, nine codons downstream. Such a rearrangement predicts a truncation of the AR, thereby deleting a large portion of the ligand-binding domain (amino acid position 768-919). Furthermore, although this mutation breaks the translational reading frame starting from codon 760, examination of the complementary DNA
\end{abstract}

F. Vilchis $(\bowtie) \cdot$ L. Ramos · B. Chávez

Department of Reproductive Biology,

Instituto Nacional de Ciencias Médicas y Nutrición

Salvador Zubirán, Vasco de Quiroga 15,

Tlalpan C.P. 14000, México D.F., México

E-mail: vilchisuf@prodigy.net.mx

Tel.: + 1-525-5731200

Fax: + 1-525-6559859

S. Kofman-Alfaro · J. C. Zenteno

Department of Genetics,

Hospital General SSA-Facultad de Medicina,

UNAM, México D.F., México

J. P. Méndez

Medical Research Unit in Developmental Biology,

Hospital de Pediatría,

CMN Siglo XXI, IMSS,

México D.F., México suggested that it does not disturb mRNA splicing. These changes have been found in all the patients and appear to account for the observed absence of detectable androgen binding to the AR in cultured fibroblasts and for the CAIS phenotype in the kindred. This disorder represents the first insertion/deletion mutation of the AR that probably arose by a slipped-strand mispairing mechanism.

Keywords Androgen insensitivity - $A R$ mutations · Insertion/deletion - Male pseudohermaphroditism · Slipped-strand mispairing

\section{Introduction}

Androgen insensitivity syndrome (AIS) is an X-linked form of male pseudohermaphroditism caused by mutations in the androgen receptor $(A R)$ gene (Lubahn et al. 1989; French et al. 1990). Impairment of AR function results in a severe virilization deficit of the external genitalia in patients with a 46,XY karyotype. The phenotype of affected individuals is variable and has been reported to range from completely female to genital ambiguity to normal male, depending on the type of mutation and its effect on AR activity (Jakubiczka et al. 1997). To date, about 250 different mutations scattered throughout the gene have been described (Chávez et al. 2001b; Gottlieb 2002). Complete AIS (CAIS) is often associated with molecular defects that may or may not affect androgen binding, including complete and partial $A R$ deletions and singlebase mutations that introduce nonsense codons into $A R$ or disrupt the splicing of the mRNA (Quigley et al. 1995). Such abnormalities almost invariably result in a non-functional or subfunctional receptor protein, causing undervirilization defects of varying degrees (McPhaul 2002; Zenteno et al. 2002).

Here, we describe a molecular study of a kindred with CAIS in which affected subjects present an unusual 
rearrangement, previously unreported in $A R$, consisting of an insertion/deletion mutation within the ligand binding domain that results in a frameshift and early stop codon.

\section{Subjects and methods}

Patients

The propositi were two siblings (aged 24 and 20 years, respectively) who were referred to our outpatient clinic because of primary amenorrhea. On clinical examination, both patients presented with a similar phenotype, characterized by female external genitalia with hypoplasia of the labia majora and minora, a short blind vagina, absence of axillary and pubic hair, and abundant breast development (Tanner 5). Cytogenetic studies revealed a 46,XY karyotype with no evidence of mosaicism in both patients. After physical and endocrinological evaluation, they were diagnosed as having CAIS (grade 7; Quigley et al. 1995). A female cousin (aged 39 years) bearing the same phenotype and her newborn niece (1 month old) presenting one left inguinal mass were included for molecular analysis. Noticeably, all patients showed a left inguinal mass corresponding to a testis, whereas ultrasonographic studies detected an intra-abdominal right testis. The pedigree of this kindred (Fig. 1A) depicts four generations, two of which include members who carry a defective AR. Studies were carried out with informed consent from the subjects or relatives (Case IV, Fig. 1A) and approval of the Ethical Committee of the Instituto Nacional de Ciencias Médicas y Nutrición Salvador Zubirán.

\section{Mutation analysis}

Coding sequence abnormalities in the $A R$ gene were assessed by exon-specific polymerase chain reaction (PCR), single-stranded conformation polymorphism (SSCP) analysis, and direct sequencing analysis. Genomic DNA was isolated from peripheral blood leukocytes of all patients and normal control males by standard methods (John et al. 1991). Exon DNA amplifications were carried out with primers and PCR conditions described previously (Chávez et al. 2001a). SSCP analysis was performed according to the method of Orita et al. (1989) with minor modifications previously described (Chávez et al. 2001b). Mutant and control PCR fragments were sequenced in both directions by using the Thermosequenase $\left(\left[\alpha-{ }^{33} \mathrm{P}\right]\right.$ ddNTP) terminator cycle sequencing kit (Amersham Life Science, Cleveland, Ohio, USA), following the manufacturer's recommendations, or by using the ABI PRISM dye terminator cycle sequencing core kit (PE Applied Biosystems, Warrington, UK) and the automated sequencing system 373 (Applied Biosystem, Foster City, Calif., USA). For cDNA analysis, total cellular RNA extracted from cultured fibroblasts was reverse-transcribed into cDNA with the SuperScript First-Strand synthesis system for reverse transcription PCR (RT-PCR; Invitrogen Life Technologies, Carlsbad, Calif., USA). Aliquots of cDNA were amplified by PCR with a set of primers designed from exon 4 (sense, 5'-GCCTCAATGAACTGGGAGAGAGACAG-3') and exon 6 (antisense, 5'-AACTCTTGAGAGAGGTGCCTCATTCG-3'). Subsequently, both mutant and control DNA fragments were purified and sequenced as described previously.

\section{Cell culture conditions}

Forearm skin-derived fibroblasts were cultured in MEM (GibcoBRL, Grand Island, N.Y., USA) containing 10\% newborn calf serum. Fibroblasts were grown to confluence at $37^{\circ} \mathrm{C}$ in $5 \% \mathrm{CO}_{2}$. Androgen-binding activity was measured in whole cells (monolayers) as previously described (Ulloa-Aguirre et al. 1988).

\section{Western blotting and immunostaining}

Cellular extracts from normal and mutant fibroblasts were immunoprecipitated by using the anti-human AR (N-20) polyclonal antibody (Santa Cruz Biotechnology, USA), which detects an epitope in the AR N-terminus, at $4^{\circ} \mathrm{C}$ for $18 \mathrm{~h}$. After addition of goat anti-rabbit $\gamma$-globulin, aliquots of the precipitates were electrophoresed on $10 \%$ polyacrylamide gels and processed for immunostaining as previously described (Larrea et al. 1993). In brief, membranes (PolyScreen PVDF; NEN LifeSci Products, Boston, Mass., USA) were fixed, blocked, and incubated overnight at room temperature in a 1:100 final dilution of AR (N-20), i.e., SC-816 polyclonal antibody in $0.01 \mathrm{~mol} / 1$ TRIS-buffered saline $\mathrm{pH} 7.4$, containing $0.1 \%$ Tween- 20 and $3.0 \%$ powdered nonfat milk. Immunocomplexes were visualized by autoradiography after incubation in ${ }^{125}$ I-labelled protein A $(200,000 \mathrm{cpm} / \mathrm{ml})$. The excess radioactivity was removed by several washes in TRISbuffered saline, and the filter was dried and autoradiographed.
Fig. 1 A Pedigree of the kindred with X-linked CAIS (circles filled with a dot heterozygous carrier females, filled squares hemizygous affected males, arrows propositi). B SSCP mutational screening showing the DNA of the propositi in the middle lanes flanked by two normal DNA controls (left lane, right lane). The exon $5{ }^{32} \mathrm{P}$-labeled PCR products were electrophoresed on neutral $5.4 \%$

polyacrylamide gels containing glycerol

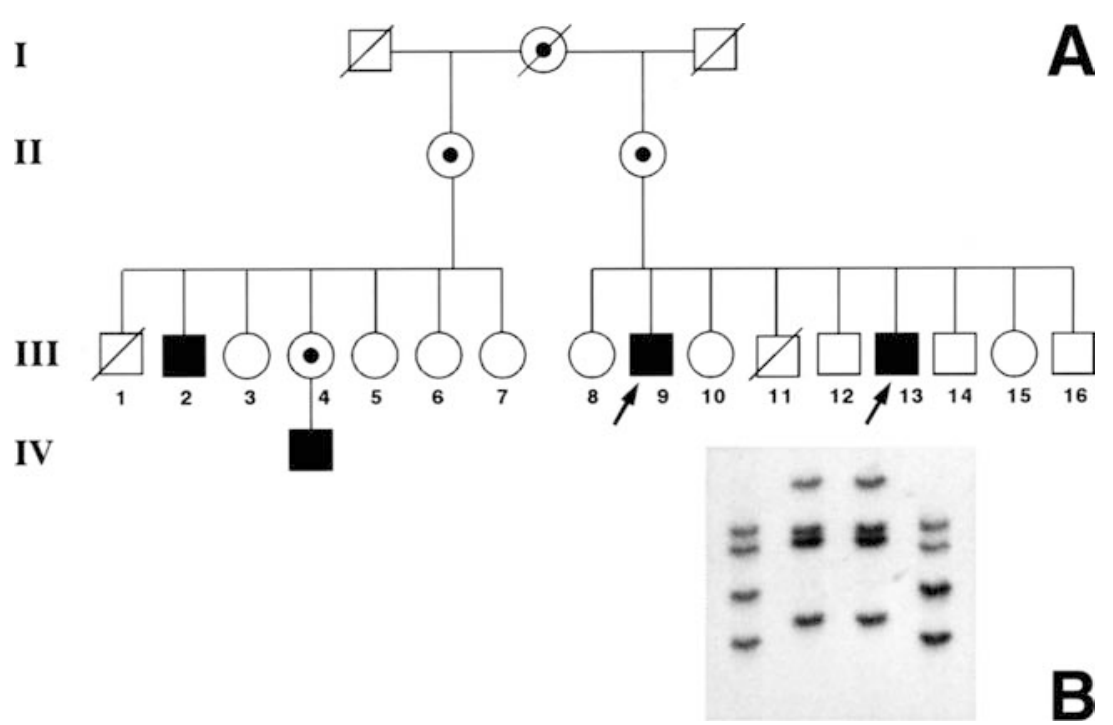




\section{Results}

Mutation detection

Molecular analysis of the $A R$ by PCR-SSCP (Fig. 1B) and DNA sequencing (Fig. 2) revealed the presence of a mutation in exon 5 leading to a gross rearrangement of the coding region. This mutation is characterized by a 7-bp deletion (g.2640_2646del AGGATGC) in combination with an 11-bp insertion, duplicating nucleotides 2652 to 2662 (ins TTCGCCCCTGA) of the 3' region of the exon. This insertion/deletion yields a frameshift at codon 760 and two premature termination signals (Fig. 2). Identical results were obtained when the mutant PCR fragments were analyzed by the automatic sequencing system (data not shown).

\section{Analysis of $A R$-mRNA by RT-PCR}

Amplification of the cDNA from mRNA by RT-PCR and its subsequent sequencing analysis confirmed the presence of the mutation and also indicated that this rearrangement does not affect normal splicing at the exon 5 /intron 5 boundary (Fig. 3). cDNA from the controls yielded an expected fragment of $273 \mathrm{bp}$, whereas those from the patients yielded a similar band with a calculated size of $277 \mathrm{bp}$ that spanned part of exon 4, the entire exon 5, and a portion of exon 6 . Examination of this cDNA showed a structural change in the coding sequence begining at codon 760 , which introduces a stop codon (TGA) downstream, at nucleotide 2639 (Fig. 3).

\section{AR-binding and Western blotting}

Androgen-binding activity of the mutant receptor was studied in a whole-cell monolayer assay. Examination of cultured skin fibroblasts indicated that the defect was characterized by the absence of $\left[{ }^{3} \mathrm{H}\right]$-dihydrotestosterone (DHT) binding. In all cases, specific $\left[{ }^{3} \mathrm{H}\right]$-DHT uptake was practically undetectable when compared with that of normal controls (Fig. 4). These results suggested that either no AR was synthesized in these cells or that an altered AR protein was produced because of an affect on mRNA translation. As seen in Fig. 4, immunoblot analysis of fibroblast extracts probed with an anti-AR polyclonal antibody showed no specific signal, suggesting an impairment in AR protein synthesis or a highly unstable truncated AR protein.

\section{Discussion}

In this report, we have presented evidence that four members from a family with CAIS carry an unusual type of mutation that alters the $A R$ open-reading frame. Sequence analysis of both genomic and cDNA has revealed a deletion/insertion mutation in the 3 ' region of exon 5, an AR segment that is considered essential for receptor stability and for maintaining a stable association of the receptor with the ligand (McPhaul et al.
Fig. 2A, B Partial sequence of $A R$ exon 5 showing a short deletion/insertion mutation in two patients with CAIS. A Sequences of a normal control and the mutation from patients III-9 and III-13 are depicted. B The 7-bp wild-type sequence AGGATGC (double underlined) is deleted and replaced by the 11-bp sequence

TTCGCCCCTGA (underlined). Mutant DNA contains two identical 11-bp sequences TTCGCCCCTCA separated by only $5 \mathrm{bp}$, suggesting that the mutation arose by a slippedstrand mispairing mechanism. Structural mutation of the AR gene results in a TGA stop codon (bottom)
A

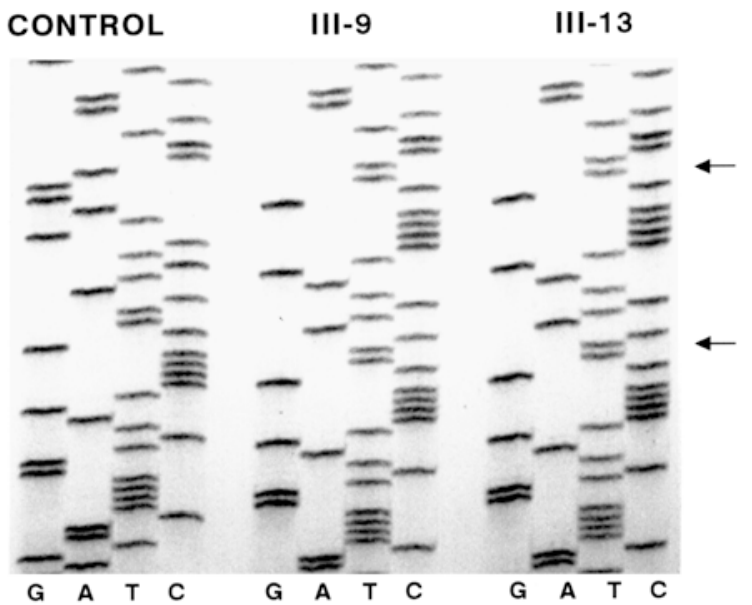

B

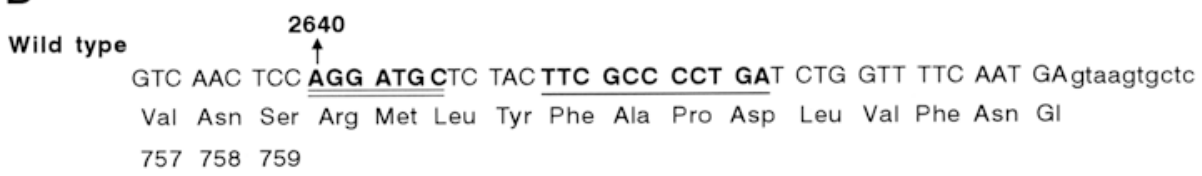

Mutant

GTC AAC TCC TTC GCC CCT GAT CTA CTT CGC CCC TGA TCT GGT TTT CAA TGA gtaagtgctC

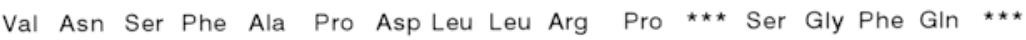
757758759 
Fig. 3A, B Sequence

comparison of nucleotides and amino acids of the mutant and wild type $A R$ cDNA and size comparison of the cDNA amplified by RT-PCR. A Sequencing analyses of the cDNA indicate that the insertion/deletion mutation in exon 5 does not affect splicing but does affect the open reading frame (ORF) starting from residue $\operatorname{Arg} 760$.

B Amplification of the cDNA segment covering exons 4-6 yielded similar bands (arrow) with a calculated size of $273 \mathrm{bp}$ and $277 \mathrm{bp}$ for the control $(C)$ and patient $(P)$, respectively ( $M W$ molecular weight markers)
WILD TYPE

$757 \quad 758 \quad 759$

GTC AAC TCC AGG ATG CTC TAC TTC GCC CCT GAT CTG GTT TTC AAT GA $\mid$ G TAC CGC ATG CAC

Val Asn Ser Arg Met Leu Tyr Phe Ala Pro Asp Leu Val Phe Asn Gl u Tyr Arg Met His

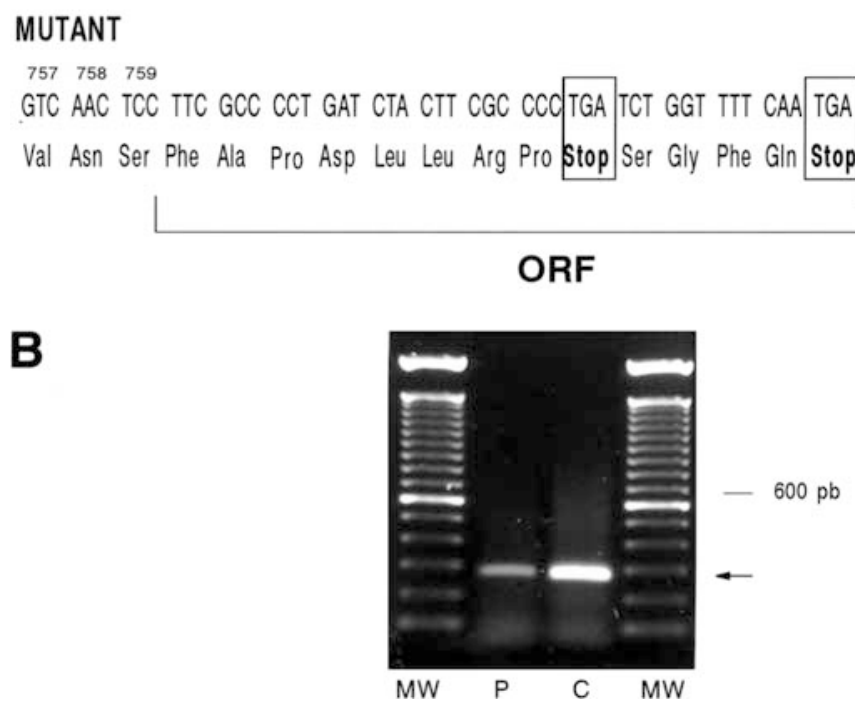

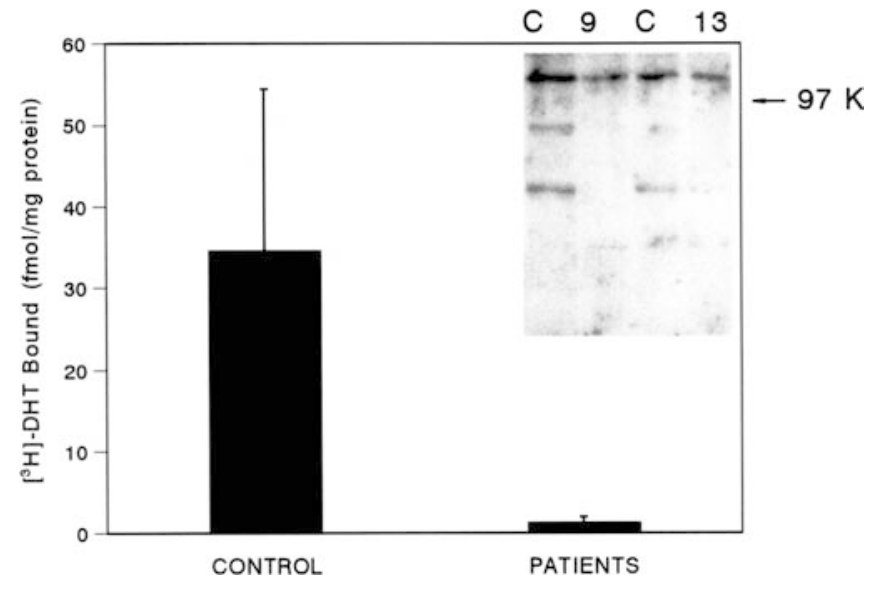

Fig. 4 Specific androgen binding and Western blot analyses from cultured skin fibroblasts. The normal range of binding is between $15 \mathrm{fmol}$ and $55 \mathrm{fmol}\left[{ }^{3} \mathrm{H}\right] \mathrm{DHT} / \mathrm{mg}$ protein. Mean values of 20 normal samples and those from patients (III-2, III-9, and III-13) are shown. Extracts of normal (C) and mutant fibroblasts (9 III-9, 13 III-13) were subjected to SDS/PAGE, transferred to nylon membranes, and probed with anti-AR (N20):SC-816 polyclonal antibody (inset). The migration pattern of phosphorylase B $(97 \mathrm{~K})$ is indicated

1993). In this particular case, the insertion appears to have arisen by duplication of a contiguous sequence (Fig. 2). This mutation putatively results in a frameshift and a new stop codon in the translated mRNA. Such changes are probably responsible for the absence of AR functional activity and therefore for the extreme phenotypic appearance observed in these patients. Similar structural disorders have been published for other genes causing human genetic diseases, where deletions and/or duplications of short sequences similarly lead to the synthesis of truncated proteins (Cooper and Krawczak 1991; Krawczak and Cooper 1991). Examples of genes that have been found to contain these types of mutations are $P C C B$ (Tahara et al. 1990), IDUA (Moskowitz et al. 1993), WT1 (Huff et al. 1995), FAA (Levran et al. 1997), HBA2 (Oron-Karni et al. 1997), and BRCA1 (Hardouin et al. 2000). More recently, a similar rearrangement to ours was found in $C Y P 27 B 1$ from a patient with $1 \alpha$-hydroxylase deficiency (Wang et al. 2002).

In all the preceding cases, these deletions/insertions could be explained by a slipped-strand mispairing mechanism initially proposed by Streisinger et al. (1966), in which one DNA strand of a repeat may be misaligned by chance with the downstream repeat of the complementary strand (Levran et al. 1997). This process has also been invoked to explain putative coupled deletion/ duplication events (Flanagan et al. 1984). Furthermore, this slippage misalignment mechanism has been proposed as an ubiquitous mechanism of mutagenesis and as being responsible for a significant proportion of mutations in mammalian cells (Kimura et al. 1994).

The 11-base insertion with a 7-base deletion found in our patients is unique, because it contains a duplication of the sequence TTCGCCCCTGA, separated by five bases. The mechanism by which this genic lesion occurred is not 
entirely clear, in particular because no direct or tandem repeats could be identified adjacent to the molecular defect. However, a careful examination of the DNA sequence involved has revealed some features previously reported to be associated with gene rearrangements. Thus, the tetranucleotide sequence CCTG (CAGG), present in the proximity of a high percentage of human gene deletions (Oron-Karni et al. 1997), is present at both sides of the rearrangement. This tetranucleotide has been observed at deletion hot spots of globin, FAA and WT1 genes, further implicating this motif in the genesis of DNA deletions (Krawczak and Cooper 1991; Huff et al. 1995; Levran et al. 1997). In addition, the TTC repeat described in the Chinese hamster APRT gene as a hot spot for spontaneous deletions (Krawczak and Cooper 1991; Smith and Adair 1996) has also been identified near and within the mutant sequence.

Based on these and other observations (Levinson and Gutman 1987; Tahara et al. 1990; Oner et al. 1991;

\section{Normal sequence \\ $* * * *$ \\ GTCAACTCCAGGATGCTCTACTTCGCCCCTGATCTGGTTTTC CAGTTGAGGTCCTACGAGATGAAGCGGGGACTAGACCAAAAG}

\section{Slippage and deletion}

GTCAACTCC-TTC

CAGTTGAGG AAGCGGGGACTAGACCAAAAG

$T G$

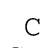

$\begin{array}{lll}\mathrm{C} & \mathrm{A} \\ \mathrm{T} & \mathrm{G}\end{array}$

A CG A

\section{Elongation and duplication}

GTCAACTCC-TTCGCCCCTGAT

CAGTTGAGG AAGCGGGGACTAGACCAAAAG

$$
\begin{array}{cccc}
C^{C} & & \text { T } \\
C & & & \\
\text { T } & & & \text { G } \\
& A & C G & A
\end{array}
$$

4. Formation of a mismatch bubble and elongation

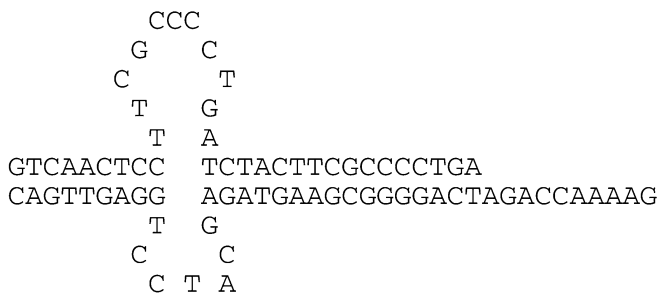

\section{Mutant sequence}

\section{GTCAACTCCTTCGCCCCTGATCTACTTCGCCCCTGA CAGTTGAGGAAGCGGGGACTAGATGAAGCGGGGACTAGACCAAAAG}

Fig. 5 Proposed model for the generation of the insertion/deletion mutation in the AR gene. Slippage at the hot spot consensus sequence CAGG/CCTG (asterisks) results in the deletion of the sequence AGGATGC. After elongation, misalignment of the resulting strand induces the formation of a bubble. Further DNA elongation results in the duplication of 11 nucleotides. The duplicated sequences are shown in bold
Tatsumi et al. 1995), we viewed a slippage-misalignment as the probable mechanism in generating this mutation. As mentioned above, it has long been recognized that small deletions and also small insertions can arise from slippage and mispairing of two homologous DNA sequences during DNA replication. This may result either in the removal and/or repetition of the DNA between these sequences (Plaseska et al. 1991). Figure 5 depicts the proposed mechanism for the formation of this rearrangement. Examination of the mutant sequence has led us to consider that the deletion and duplication may have occurred in a sequential fashion. Initially, the deletion of seven nucleotides (AGGATGC) may have arisen from slippage induced by the CAGG tetranucleotide (step 2). After extension (step 3) and as a consequence of an incorrect mispairing, the resulting strands probably formed a mismatch bubble, where the sequence TTCGCCCCTGA was mismatched (step 4). Further DNA elongation may have led to the duplication of 11 nucleotides (step 5). The final result of these structural disorders is a modified sequence that affects the reading frame starting from codon 760 . Thus, the gene mutation described here (g.2640_2646del7/2652_2662ins11) would encode for an inactive AR, primarily because of its inability to bind testosterone or DHT, a prerequisite for transcriptional activation. As a consequence of such a genetic defect, target genes in affected patients may be unresponsive, even to high doses of androgens, which necessarily leads to androgen resistance and the development of CAIS. To our knowledge, this is the first case of familial CAIS attributable to an insertion/ deletion mutation in $A R$.

Acknowledgements This study was partially supported by CONACYT (México), Grant 0010P-M.

\section{References}

Chávez B, Vilchis F, Zenteno JC, Larrea F, Kofman-Alfaro S (2001a) Novel molecular defects in the androgen receptor gene of Mexican patients with androgen insensitivity. Clin Genet 59:185-188

Chávez B, Méndez JP, Ulloa-Aguirre A, Larrea F, Vilchis F (2001b) Eight novel mutations of the androgen receptor gene in patients with androgen insensitivity syndrome. J Hum Genet 46:560-565

Cooper DN, Krawczak M (1991) Mechanisms of insertational mutagenesis in human genes causing genetic disease. Hum Genet 87:409-415

Flanagan JG, Lefranc MP, Rabbitts TH (1984) Mechanisms of divergence and convergence of the human immunoglobulin $\alpha-1$ and $\alpha-2$ constant region gene sequences. Cell 36:681-688

French FS, Lubahn DB, Brown TR, Simental AJ, Quigley CA, Yarbrough WG, Tan J, Sar M, Joseph DR, Evans BAJ, Hughes IA, Migeon CJ, Wilson EM (1990) Molecular basis of androgen insensitivity. Recent Prog Horm Res 46:1-42

Gottlieb B (2002) Androgen receptor gene mutations database, http://www.mcgill.ca/androgendb/

Hardouin A, Baumann JJ, Roussel G, Quillien V, Dugast C, Berther P (2000) A new mutation in the BRCA1 gene. Hum Mutat (report 202), online 
Huff V, Jaffe N, Saunders GF, Strong LC, Villalba F, Ruteshouser EC (1995) WT1 exon 1 deletion/insertion mutations in Wilms tumor patients, associated with di- and trinucleotide repeats and deletion hotspots consensus sequences. Am J Hum Genet 56:84-90

Jakubiczka S, Nedel S, Werder EA, Schleiermacher E, Theile U, Wolff G, Wieacker P (1997) Mutations of the androgen receptor gene in patients with complete androgen insensitivity. Hum Mutat 9:57-61

John SWM, Weilzner G, Rozen R, Scriver CR (1991) A rapid procedure for extracting genomic DNA from leukocytes. Nucleic Acids Res 19:408

Kimura H, Iyehara-Ogawa H, Kato T (1994) Slippage-misalignment: to what extent does it contribute to mammalian cell mutagenesis? Mutagenesis 9:395-400

Krawczak M, Cooper DN (1991) Gene deletions causing human genetic disease: mechanisms of mutagenesis and the role of the local DNA sequence environment. Hum Genet 86:425-441

Larrea F, Méndez I, Parra A, Espinosa A (1993) Serum pattern of different molecular forms of prolactin during normal human pregnancy. Hum Reprod 8:1617-1622

Levinson G, Gutman GA (1987) Slipped-strand mispairing: a major mechanism for DNA sequence evolution. Mol Biol Evol 4:203-221

Levran O, Erlich T, Magdalena N, Gregory JJ, Batish ST, Verlander PC, Auerbach AD (1997) Sequence variation in the Fanconi anemia gene $F A A$. Proc Natl Acad Sci USA 94:13051-13056

Lubahn DB, Brown TR, Simental JA, Higgs HN, Migeon CJ, Wilson EM, French FS (1989) Sequence of the intron/exon junctions of the coding region of the human androgen receptor gene and identification of a point mutation in a family with complete androgen insensitivity. Proc Natl Acad Sci USA 86:9534-9538

McPhaul MJ (2002) Molecular defects of the androgen receptor. Recent Prog Horm Res 57:181-194

McPhaul MJ, Marcelli M, Zoppi S, Griffin J E, Wilson J D (1993) The spectrum of mutations in the androgen receptor gene that causes androgen resistance. J Clin Endocrinol Metab 76:17-23

Moskowitz SM, Tieu PT, Neufeld EE (1993) A deletion/insertion mutation in the IDUA gene in a Libyan Jewish patient with Hurler syndrome (mucopolysaccharidosis IH). Hum Mutat 2:71-73

Oner R, Oner C, Wilson JB, Tamagnini GP, Ribeiro LML, Huisman THJ (1991) Dominant $\beta$-thalassaemia trait in a Portuguese family is caused by a deletion of (G)TGGCTGGTGT(G) and an insertion of $(\mathrm{G}) \mathrm{GCAG}(\mathrm{G})$ in codons $134,135,136$ and 137 of the $\beta$-globin gene. Br J Haematol 79:306-310

Orita M, Suzuki Y, Hayashi K (1989) Rapid and sensitive detection of point mutations and DNA polymorphisms using polymerase chain reaction. Genomics 5:874-879

Oron-Karni V, Filon D, Rund D, Oppenheim A (1997) A novel mechanism generating short deletion/insertions following slippage is suggested by a mutation in the human $\alpha 2$-globin gene. Hum Mol Genet 6:881-885

Plaseska D, Dimovski AJ, Wilson JB, Webber BB, Hume HA, Huisman THJ (1991) Hemoglobin Montreal: a new variant with an extended $\beta$ chain due to a deletion of Asp, Gly, Leu at positions 73, 74, and 75, and an insertion of Ala, Arg, Cys, Gln at the same location. Blood 77:178-181

Quigley CA, De Bellis A, Marschke KB, El-Awady MK, Wilson EM, French FS (1995) Androgen receptor defects: historical, clinical, and molecular perspectives. Endocr Rev 16:271-321

Smith DG, Adair GM (1996) Characterization of an apparent hotspot for spontaneous mutation in exon 5 of the Chinese hamster APRT gene. Mutat Res 352:87-96

Streisinger G, Okada Y, Emrich J, Tsugita A, Terzaghi E, Inouye M (1966) Frameshift mutation and the genetic code. Cold Spring Harb Symp Quant Biol 31:77-84

Tahara T, Kraus JP, Rosenberg LE (1990) An unusual insertion/ deletion in the gene encoding the $\beta$-subunit of propionyl-CoA carboxylase is a frequent mutation in Caucasian propionic acidemia. Proc Natl Acad Sci USA 87:1372-1376

Tatsumi N, Inui K, Sakai N, Fukushima H, Nishimoto J, Yanagihara I, Nishigaki T, Tsukamoto H, Fu L, Taniike M, Okada S (1995) Molecular defects in Krabbe disease. Hum Mol Genet 4:1865-1868

Ulloa-Aguirre A, Chávez B, Méndez JP, Saavedra D, Perez-Palacios $G$ (1988) Inherited impairment of nuclear androgen uptake as a cause of familial androgen insensitivity. Eur J Obstet Gynecol Reprod Biol 28:317-329

Wang X, Zhang MYH, Miller W, Portale AA (2002) Novel gene mutations in patients with $1 \alpha$-hydroxylase deficiency that confer partial enzyme activity in vitro. J Clin Endocrinol Metab $87: 2424-2430$

Zenteno JC, Chávez B, Vilchis F, Kofman-Alfaro S (2002) Phenotypic heterogeneity associated with identical mutations in residue 870 of the androgen receptor. Horm Res 57:90-93 